\title{
Viabilidade celular da fração mononuclear da medula óssea e fração vascular estromal do tecido adiposo de equinos após o processo de congelamento e descongelamento ${ }^{1}$
}

\author{
Gesiane Ribeiro², Cristina O. Massoco ${ }^{3 *}$ e José Corrêa de Lacerda Neto ${ }^{4}$
}

\begin{abstract}
Ribeiro G., Massoco C.O. \& Lacerda Neto J.C. 2012. [Viability of equine bone marrow mononuclear fraction and adipose tissue-derived stromal vascular fraction after freezing and thawing process.] Viabilidade celular da fração mononuclear da medula óssea e fração vascular estromal do tecido adiposo de equinos após o processo de congelamento e descongelamento. Pesquisa Veterinária Brasileira 32(Supl.1):118-124. Departamento de Patologia Veterinária, Faculdade de Medicina Veterinária e Zootecnia, Universidade de São Paulo, Av. Prof. Dr. Orlando Marques de Paiva 87, Cidade Universitária, São Paulo, SP 05508-270, Brazil. E-mail: cmassoco@usp.br

In five adult horses, bone marrow was aspirated from the sternum and adipose tissue extracted from the gluteal region. The samples were processed to obtain the mononuclear fraction of bone marrow and stromal vascular fraction of adipose tissue, and the number of cells obtained and cell viability were determined. Next, the cell samples were frozen in medium containing $20 \%$ fetal bovine serum and $10 \%$ dimethylsulfoxide. After one month, the cells were thawed and cell viability was again determined. The results revealed that the techniques for collecting both bone marrow and adipose tissue in horses are simple, rapid and safe. The methods used for processing the samples were efficient, yielding about $95 \%$ cell viability. After freezing, mean viability of the mononuclear cells of bone marrow was $86 \%$, and $64 \%$ for the stromal vascular cells of adipose tissue. In view of the importance of cell therapy in equine clinical medicine, it is concluded that further studies are needed for the standardization of a cryopreservation technique to maintain the integrity for the mononuclear fraction of bone marrow and the stromal vascular fraction of adipose tissue in horses.
\end{abstract}

INDEX TERMS: Cryopreservation, bone marrow, adipose tissue, cell viability, equidae.

RESUMO.- Cinco cavalos adultos foram submetidos à coleta de medula óssea do esterno e de tecido adiposo da região glútea. As amostras foram processadas para obtenção da fração mononuclear da medula óssea e fração vascular estromal do tecido adiposo, o número de células obtidas e a

\footnotetext{
${ }^{1}$ Recebido em 29 de setembro de 2012.

Aceito para publicação em 1 de dezembro de 2012.

${ }^{2}$ Faculdades Metropolitanas Unidas (FMU), Campus Ponte Estaiada, Rua Ministro Nelson Hungria 541, Real Parque-Morumbi, São Paulo, SP 05690-050, Brasil. E-mail: gesiane@usp.br

${ }^{3}$ Departamento de Patologia, Faculdade de Medicina Veterinária e Zootecnia da Universidade de São Paulo (USP). Av. Prof. Dr. Orlando Marques de Paiva 87, Cidade Universitária, São Paulo, SP 05508-270, Brasil. *Autor para correspondência: cmassoco@usp.br

${ }^{4}$ Departamento de Clínica e Cirurgia Veterinária, Faculdade de Ciências Agrárias e Veterinárias da Universidade Estadual Paulista (Unesp), Via de Acesso Prof. Paulo Donato Castellane s/n, Jaboticabal, SP 14884-900, Brasil. E-mail: jlacerda@fcav.unesp.br
}

viabilidade celular foram determinados. Em seguida, realizou-se o congelamento das amostras em solução contendo $20 \%$ de soro fetal bovino e $10 \%$ de dimetilsulfóxido. Depois de um mês, realizou-se o descongelamento das amostras e a viabilidade celular foi novamente mensurada. Os resultados revelaram que as técnicas utilizadas tanto para coleta de medula óssea quanto de tecido adiposo em equinos são simples, rápidas e seguras. As metodologias adotadas para o processamento das amostras foram eficientes, obtendo-se aproximadamente $95 \%$ de viabilidade celular. Após o descongelamento, a viabilidade média das amostras de células mononucleares da medula óssea foi de $86 \%$ e da fração vascular estromal do tecido adiposo de $64 \%$. Frente à importância da terapia celular na clínica médica de equinos, concluiu-se que é necessária a realização de mais estudos, visando padronizar uma técnica de criopreservação que mantenha a integridade das células da fração mono- 
nuclear da medula óssea e da fração vascular estromal do tecido adiposo de equinos.

TERMOS DE INDEXAÇÃO: Criopreservação, equideos, medula óssea, tecido adiposo, viabilidade celular.

\section{INTRODUÇÃO}

As células do estroma medular, também conhecidas como células-tronco mesenquimais, são células-tronco multipotentes não hematopoiéticas. Essas células têm a capacidade de se renovar e diferenciar em várias linhagens de tecido conjuntivo, incluindo ossos, cartilagens, tendões e músculos, o que têm atraído a atenção de vários pesquisadores, despertando grande interesse no tratamento de tecidos lesados de origem mesenquimal (Bittencourt et al. 2006).

0 uso de células-tronco mesenquimais autólogas no tratamento de lesões musculoesqueléticas em cavalos pode ter um custo elevado e não é uma opção terapêutica disponível imediatamente no momento do diagnóstico porque necessita de um tempo de cultura in vitro para expansão celular. Por outro lado, o aspirado de medula óssea é um material obtido praticamente sem custo, com poucos equipamentos, e que permite o uso imediato. 0 aspirado medular normalmente é centrifugado para concentrar plaquetas e a população de células mononucleares (que contém células-tronco mesenquimais). Assim, o número de células-tronco mesenquimais no aspirado de medula óssea pode ser rapidamente aumentado no local de coleta, sem a etapa de cultura in vitro (Gutierrez-Nibeyro 2011). Além disso, o aspirado de medula óssea contém os três componentes necessários para uma ótima regeneração tecidual: scaffold, fatores de crescimento e células-tronco (Fortier \& Smith 2008).

0 aspirado medular tem sido utilizado para induzir formação óssea em humanos com defeitos ósseos, não-união ou osteonecrose. Em cavalos, o aspirado de medula óssea está sendo usado com bons resultados no reparo de cartilagens, ossos e tendões (Gutierrez-Nibeyro 2011). Oliveira et al. (2011) utilizaram células da fração mononuclear da medula óssea no tratamento de tendinites induzidas em equinos e observaram melhora na organização tecidual, com maior alinhamento das fibras e maior percentual de redução da área lesada.

Apesar de a medula óssea ser a fonte de células-tronco mais estudada, ela não é a única. A presença de células multipotentes com extensiva capacidade de auto-renovação tem sido descrita em outros tecidos do organismo (Toma et al. 2001). Zuk et al. (2002) confirmaram a presença e a capacidade de diferenciação de células-tronco isoladas de lipoaspirados humanos, fenotipicamente muito semelhantes às células-tronco mesenquimais isoladas da medula óssea, concluindo que o tecido adiposo representa uma fonte de células-tronco adultas. Segundo Gutierrez-Nibeyro (2011), células da fração vascular estromal do tecido adiposo têm sido usadas no tratamento de lesões em tendões e ligamentos de equinos, com resultados aparentemente satisfatórios. Nixon et al. (2008) avaliaram a aplicação intralesional da fração vascular estromal de tecido adiposo no tratamento de tendinite induzida experimentalmente em cavalos e verificaram que os tendões tratados apresentaram melhor organização histológica e menor infiltrado de células inflamatórias que o grupo controle.

De acordo com Zuk et al. (2001), a fonte ideal de células-tronco autólogas seria aquela que fosse de fácil obtenção, resultando em mínimo desconforto para o paciente, e capaz de produzir um número substancial de células. Em medicina veterinária, o conhecimento sobre estas células ainda é bastante limitado e elas estão sendo utilizadas com a hipótese de que suas características essenciais sejam as mesmas para todas as espécies (Vidal et al. 2007). Porém, segundo Fraser et al. (2008), pode-se dizer que células-tronco provenientes do tecido adiposo e da medula óssea de um mesmo indivíduo não são idênticas justificando, portanto, a necessidade de estudos que busquem informações sobre células obtidas de diferentes fontes.

Segundo Renzi et al. (2012), com o advento das terapias celulares, surge a necessidade de particular conhecimento sobre procedimentos laboratoriais, que garanta não apenas a contínua produção de células, mas também que preserve a identidade e integridade da célula o mais próximo possível da original. A criopreservação a temperaturas abaixo de $-80^{\circ} \mathrm{C}$ e, muitas vezes, abaixo de $-140^{\circ} \mathrm{C}$ é um assunto de importância primordial. Na espécie equina, por exemplo, muito pouco se sabe a respeito dos efeitos da criopreservação sobre a viabilidade celular.

Em determinadas situações, a criopreservação e estocagem de células são necessárias para posterior utilização, e o conhecimento dos mecanismos físico-químicos que ocorrem durante o congelamento e descongelamento é de suma importância para manter a estrutura e integridade funcional das células e tecidos congelados (Meryman 2007). A lesão celular induzida pelo congelamento se explica pela formação de cristais de gelo, nos meios intra e extracelular, que ocorrem em diferentes temperaturas durante o congelamento. Estes eventos podem ocasionar prejuízos às células por mecanismos diretos ou por intermédio do desequilíbrio osmótico (Sumida 2006).

Segundo Pegg (2006), a utilização de crioprotetores e protocolos com controle de temperatura visa diminuir as perdas celulares inerentes ao processo de congelamento. A adição de agentes crioprotetores penetrantes, tais como o dimetilsulfóxido (DMSO), visa diminuir o volume de água para formação de cristais de gelo. Além disso, os agentes crioprotetores aumentam a concentração de soluto e reduzem as diferenças de osmolaridade, protegendo as células dos efeitos deletérios do desequilíbrio osmótico entre os meios intra e extracelular (Meryman 2007).

O objetivo deste trabalho foi determinar a viabilidade celular da fração mononuclear da medula óssea e da fração vascular estromal do tecido adiposo de equinos antes e após o processo de criopreservação utilizando DMSO.

\section{MATERIAL E MÉTODOS}

\section{Animais}

A realização deste trabalho foi aprovada pelo Comitê de Ética e Bem Estar Animal (CEBEA) da Faculdade de Ciências Agrárias e Veterinárias da Universidade Estadual Paulista (Unesp), Campus de Jaboticabal/SP, por meio do Protocolo no 013041-5. 
Foram utilizados cinco equinos mestiços, machos, com idade média e desvio padrão de 11 anos $\pm 3,71$ e peso variando de 400 $500 \mathrm{~kg}$, provenientes da Fazenda do Serviço de Soroprodução do Instituto Butantã, localizada na cidade de São Roque/SP. Foram incluídos neste estudo apenas os animais hígidos selecionados após exame clínico geral e que não estavam sendo utilizados nos protocolos de imunização do Instituto.

Cada animal foi submetido a dois tipos de coleta. Inicialmente foi realizado o aspirado de medula óssea e, em seguida, a coleta de tecido adiposo subcutâneo.

As coletas e o processamento foram realizados no mesmo dia e, durante o transporte até o laboratório, as amostras foram mantidas sob refrigeração.

\section{Medula óssea}

As amostras de medula óssea foram coletadas do esterno de cada cavalo por meio de punção biópsia aspirativa. 0 procedimento foi realizado com o animal em posição quadrupedal, contido por um cabresto.

0 local da biópsia foi tricotomizado e preparado para coleta estéril. A pele e tecidos adjacentes às esternébras foram anestesiados através da infiltração de $5 \mathrm{~mL}$ de cloridrato de lidocaína a $2 \%$ com vasoconstritor (Xilestesin ${ }^{\circledR}$, Cristália, Itapira, SP, Brasil). A punção foi realizada com a introdução de um madril de cateter 14G (Nipro Medical Ltda, Sorocaba, SP, Brasil) no interior da quinta esternébra e a aspiração (Fig.1). foi feita com seringa de $20 \mathrm{~mL}$ contendo $0,2 \mathrm{~mL}$ de heparina sódica (Liquemine ${ }^{\circledR}$, Roche Brasil, Rio de Janeiro, RJ, Brasil).

\section{Tecido adiposo}

As amostras de tecido adiposo foram coletadas da gordura localizada sobre a superfície dorsal do músculo glúteo, próximo à inserção da cauda. 0 procedimento foi realizado com o animal em posição quadrupedal mantido em tronco de contenção.

A região foi tricotomizada, anestesiada com infiltração local

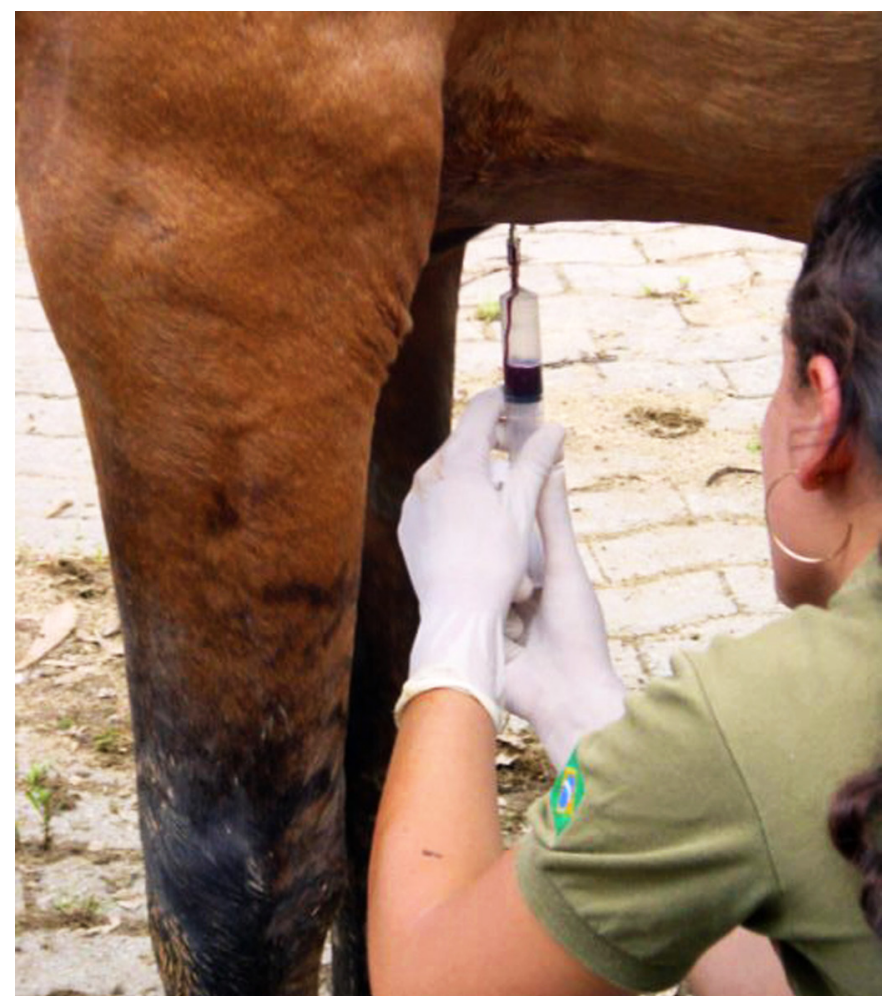

Fig.1. Coleta de medula óssea em equino. de cloridrato de lidocaína a $2 \%$ com vasoconstritor (Xilestesin ${ }^{\circledR}$, Cristália, Itapira, SP, Brasil) e preparada para uma coleta estéril. Foi realizada uma incisão de pele, de aproximadamente $5,0 \mathrm{~cm}$, e leve divulsão do tecido subcutâneo para exposição e coleta de uma amostra de tecido adiposo. Em seguida, a pele foi aproximada com fio de nylon n.0 (Brasuture, São Sebastião da Grama, SP, Brasil) em pontos simples separados. 0 material coletado foi acondicionado em tubos contendo meio de cultivo RPMI-1640 (Cultilab, Campinas, SP, Brasil) e mantido sob refrigeração (Fig.2A,C) em caixa térmica durante o transporte até o laboratório.

\section{Isolamento da fração mononuclear da medula óssea e fração vascular estromal do tecido adiposo}

As amostras de aspirado medular foram diluídas em HBSS (Solução Balanceada Hanks, Cultilab, Campinas, SP, Brasil) na proporção de 1:1 e, em seguida, processadas para o isolamento de células mononucleares, adicionando-se lentamente Ficoll-Paque (1070g/L) (Amersham, São Paulo, SP, Brasil) na proporção de 1:1 e centrifugando-se a $350 \mathrm{~g}$ por 30 minutos. Após a centrifugação, formou-se um halo esbranquiçado no meio do tubo contendo as células mononucleares, que foram aspiradas e lavadas duas vezes com HBSS.

Para obtenção da fração vascular estromal, as amostras de tecido adiposo de cada cavalo foram fragmentadas em placa de Petri (Corning, Midland, Michigan, USA) estéril utilizando-se lâminas de bisturi (Embramac, Itapira, SP, Brasil) e colocadas em solução de RPMI-1640 (Cultilab, Campinas, SP, Brasil) contendo 0,3 mg/ $\mathrm{mL}$ de colagenase tipo I (Sigma-Aldrich, Sto Louis, MO, USA) para a digestão do tecido conjuntivo a $37^{\circ} \mathrm{C}$ por aproximadamente duas horas sob agitação. Em seguida, a suspensão celular foi filtrada com o auxílio de um filtro de nylon diâmetro de 100 micras (Millipore, USA) e centrifugada a $300 \mathrm{~g}$ por dez minutos a $4^{\circ} \mathrm{C}$. 0 pellet recuperado após centrifugação foi ressuspenso em 8mL de HBSS.

O número de células viáveis da fração mononuclear da medula óssea e da fração vascular estromal do tecido adiposo foi determinado pela técnica de exclusão de células não viáveis coradas pelo corante vital azul de Trypan a 0,2\% (Gibco Invitrogen, São Paulo, SP, Brasil).

\section{Técnica de Congelamento}

0 congelamento das amostras foi realizado conforme a metodologia descrita por Martinello et al. (2010) com modificações. As células foram congeladas na concentração de $1 \times 10^{6}$ células $/ \mathrm{mL}$, em solução criopreservativa sem antibiótico e/ou antimicótico contendo 20\% de soro fetal bovino (SFB) (Cultilab, Campinas, SP, Brasil) e 10\% de DMSO (Sigma-Aldrich, St Louis, MO, USA), em tubos criogênicos (Corning, Midland, Michigan, USA) acondicionados em racks (Corning, Midland, Michigan, USA) onde ficaram emergidos em álcool isopropílico durante 24 horas a $-80^{\circ} \mathrm{C}$, sendo posteriormente armazenadas em nitrogênio líquido. Os tubos criogênicos foram identificados com o tipo de célula, data e concentração.

Após um mês congeladas, as células foram descongeladas colocando-se os criotubos rapidamente em banho-maria a $37^{\circ} \mathrm{C}$ e, assim que foi visualizado o início do descongelamento, as células foram ressuspensas em meio RPMI-1640 a $37^{\circ} \mathrm{C}$ contendo $10 \%$ de SFB e centrifugadas a $300 \mathrm{~g}$ por 10 minutos (este passo foi realizado duas vezes). 0 sobrenadante foi descartado e o pellet celular foi reconstituído com $1 \mathrm{~mL}$ de RPMI-1640 com SFB a 10\% e a viabilidade celular foi novamente avaliada após a centrifugação utilizando-se o corante vital Azul de Trypan.

\section{Análise estatística}

A comparação da concentração celular observada nos aspirados de medula óssea do esterno (células/ml) e de tecido adiposo 

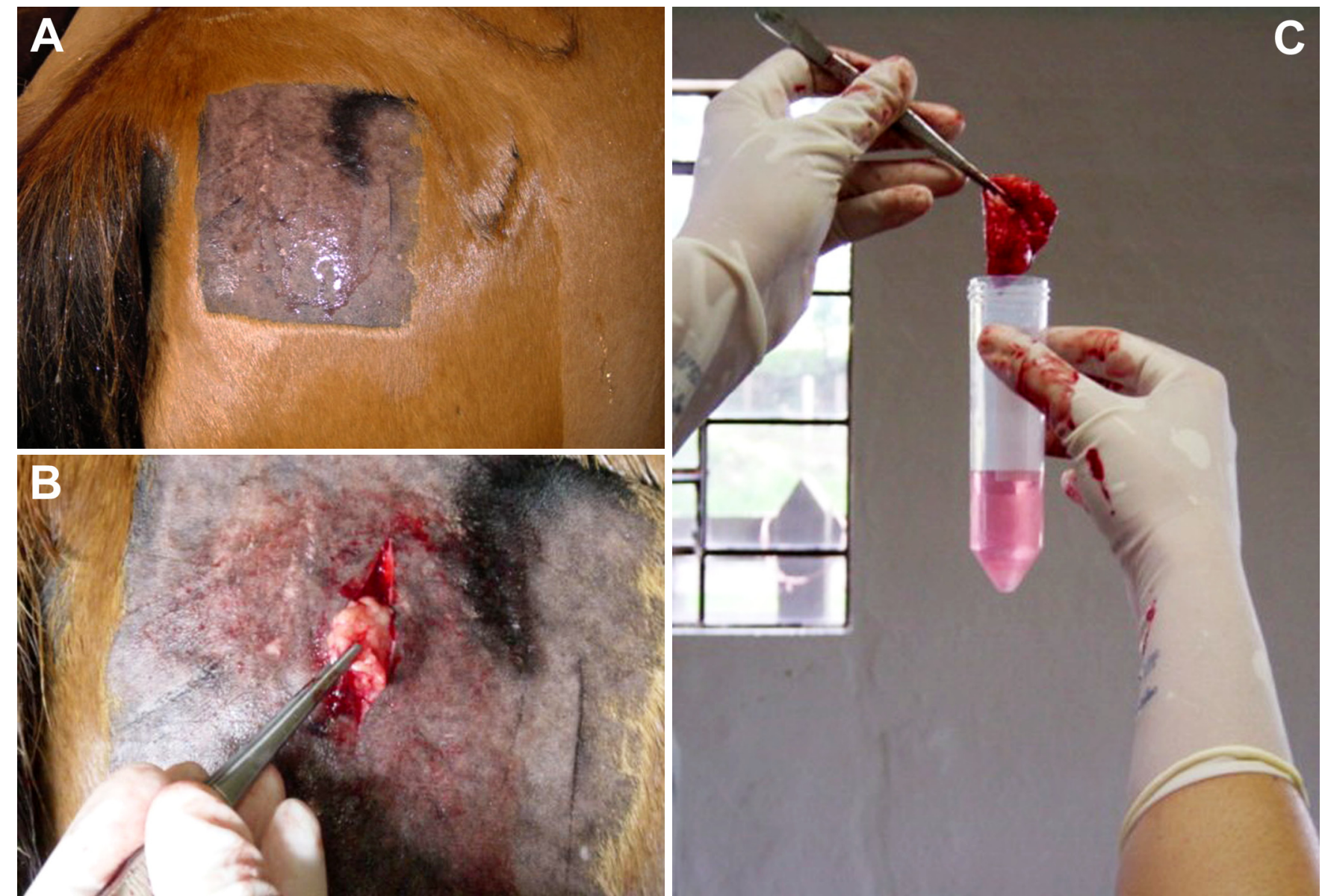

Fig.2. Coleta de tecido adiposo em equinos.

da região glútea (células/g) foi realizada por meio do teste U de Mann-Whitney. A escolha pelo teste não paramétrico foi baseada no tamanho das amostras $\left(\mathrm{n}_{\mathrm{MO}}=5\right.$ e $\left.\mathrm{n}_{\mathrm{AD}}=5\right)$. Para tanto, o pacote estatístico SPSS v. 9 foi utilizado. Considerou-se nível de significância de 0,05. Esta mesma prova foi adotada a fim de comparar viabilidade celular (\%) segundo o tipo de tecido coletado, medular ou adiposo, nos dois momentos de estudo $(\alpha=0,05)$.

Uma análise pareada por meio da prova de Wilcoxon foi conduzida no intuito de verificar se havia diferença significativa entre a viabilidade celular (\%) observada antes e após o congelamento $(\alpha=0,05)$.

\section{RESULTADOS}

A coleta de medula óssea do esterno de equinos foi considerada um procedimento bastante simples e de fácil execução. Em virtude do temperamento dócil dos animais utilizados, a coleta foi realizada com os cavalos contidos por um cabresto, fora do tronco de contenção, e não foi necessária a utilização de tranquilizantes.

Após a introdução da agulha na cavidade medular, o mandril foi retirado e o aspirado de medula óssea foi obtido tracionando-se o êmbolo da seringa. A força de tração necessária para obter-se a amostra variou entre os animais, bem como a quantidade de material coletado, como pode ser observado no Quadro 1.

Em relação à coleta de tecido adiposo, também foi considerada simples e fácil. Não houve necessidade de tranquilização, mas os animais permaneceram em tron-
Quadro 1. Volume (ml) de aspirado da medula óssea do esterno e quantidade (g) de tecido adiposo da região glútea de cinco equinos

\begin{tabular}{ccc}
\hline Animal & Aspirado medular $(\mathrm{mL})$ & Tecido adiposo (g) \\
\hline 1 & 15,0 & 8,1 \\
2 & 40,0 & 28,6 \\
3 & 37,0 & 15,8 \\
4 & 24,0 & 8,0 \\
5 & 40,0 & 6,7 \\
Média \pm Desvio Padrão & $31,2 \pm 11,2$ & $13,44 \pm 9,2$
\end{tabular}

co de contenção durante o procedimento para garantir a segurança do pesquisador, que precisou subir em um banco por não ter altura suficiente para acessar a região glútea dos animais. A anestesia local foi suficiente para impedir qualquer estímulo doloroso e o uso do cloridrato de lidocaína com vasoconstritor foi importante para minimizar o sangramento durante a coleta, evitando contaminação da amostra. A quantidade de material coletado foi bastante variável entre os animais e está apresentada no Quadro 1.

Após o processamento das amostras, foram obtidas as células mononucleares da medula óssea e da fração vascular estromal do tecido adiposo. 0 número de células obtidas a partir de $1 \mathrm{~mL}$ de aspirado medular e $1 \mathrm{~g}$ de tecido adiposo está apresentado no Quadro 2. Não foi observada diferença significativa entre a concentração de células mononucleares viáveis a partir de aspirado de medula óssea 
Quadro 2. Número de células mononucleares viáveis obtidas a partir da medula óssea (MO) e tecido adiposo (AD) de equinos

\begin{tabular}{ccc}
\hline Animal & Células/mL MO & Células $/ g$ AD \\
\hline 1 & $11,2 \times 10^{5}$ & $6,17 \times 10^{5}$ \\
2 & $3,40 \times 10^{5}$ & $8,39 \times 10^{5}$ \\
3 & $21,6 \times 10^{5}$ & $1,27 \times 10^{5}$ \\
4 & $20,3 \times 10^{5}$ & $2,00 \times 10^{5}$ \\
5 & $37,8 \times 10^{5}$ & $5,97 \times 10^{5}$ \\
Média \pm Desvio Padrão & $18,86 \times 10^{5} \pm 12,9 \times 10^{5}$ & $4,76 \times 10^{5} \pm 3,02 \times 10^{5}$ \\
Mediana & $20,3 \times 10^{5}$ & $5,97 \times 10^{5}$
\end{tabular}

Quadro 3. Porcentagem de viabilidade celular obtida após o processamento das amostras de medula óssea (MO) e tecido adiposo (AD) em equinos

\begin{tabular}{ccc}
\hline Animal & \% Viabilidade MO & \% Viabilidade AD \\
\hline 1 & 94 & 100 \\
2 & 93 & 92 \\
3 & 96 & 100 \\
4 & 94 & 88 \\
5 & 96 & 100 \\
Média \pm Desvio Padrão & $94,6 \pm 1,34$ & $96 \pm 5,66$ \\
Mediana & 94 & 100
\end{tabular}

Quadro 4. Porcentagem de viabilidade de células da medula óssea (MO) e células do tecido adiposo (AD) obtida após o descongelamento das amostras

\begin{tabular}{ccc}
\hline Animal & \% Viabilidade MO & \% Viabilidade AD \\
\hline 1 & 83 & 81 \\
2 & 88 & 55 \\
3 & 82 & 77 \\
4 & 91 & 60 \\
5 & 86 & 50 \\
Média \pm Desvio Padrão & $86 \pm 3,28$ & $64,6 \pm 12,2$ \\
Mediana & 86 & 60
\end{tabular}

e de tecido adiposo $(\mathrm{p}=0,056)$ apesar de haver uma clara diferença entre os valores médios e medianos.

A metodologia utilizada para o processamento das amostras foi considerada simples e muito eficiente, uma vez que foi obtido um alto percentual de viabilidade celular tanto para as amostras de aspirado medular quanto para as de tecido adiposo (Quadro 3), não havendo diferença estatística entre os dois tipos de tecido $(\mathrm{p}=0,690)$.

Após o descongelamento das amostras verificou-se que a viabilidade celular média da fração mononuclear da medula óssea diminuiu de aproximadamente $95 \%$ antes do congelamento (Quadro 3) para 86\% (Quadro 4). Na fração vascular estromal de tecido adiposo a viabilidade celular média caiu de $96 \%$ para aproximadamente $65 \%$. A comparação da viabilidade celular entre os dois momentos de estudo indicou a existência de diferença significativa tanto para as amostras obtidas da medula óssea $(p=0,043)$, quanto para as amostras de tecido adiposo $(\mathrm{p}=0,043)$. Em ambos os casos, as viabilidades médias e medianas foram maiores nas amostras analisadas antes do congelamento.

\section{DISCUSSÃO}

Embora ainda seja limitada a pesquisa nesta área, a literatura recente indica o uso da terapia celular em lesões mus- culoesqueléticas de equinos e, como o campo da medicina regenerativa celular está em constante evolução, os pesquisadores ainda procuram encontrar qual é a opção terapêutica mais efetiva para proporcionar aos clínicos a melhor ferramenta (Gutierrez-Nibeyro 2011).

As células-tronco mesenquimais oriundas da medula óssea têm sido utilizadas com sucesso no tratamento de cavalos com lesões tendíneas (Pacini et al. 2007). Entretanto, Crovace et al. (2010) observaram que a terapia com células-tronco mesenquimais derivadas de medula óssea é tão efetiva no tratamento de lesões tendíneas induzidas com colagenase quanto o simples aspirado medular. Ambos os tratamentos foram capazes de melhorar a cicatrização do tendão e a organização da matriz extracelular. Oliveira et al. (2011) também observaram melhora na qualidade da cicatrização tendínea com a utilização da fração mononuclear de aspirado medular.

Alguns autores relataram o risco de potenciais complicações associadas à coleta de medula do esterno em cavalos, como pneumotórax e pneumopericárdio, além da posição precária e vulnerável do pesquisador durante a coleta (Durando et al. 2006). Entretanto, de acordo com Smith et al. (2003), o procedimento é extremamente simples e pode ser realizado apenas com a utilização de tranquilizantes e anestesia local. Neste trabalho, comprovou-se a facilidade do procedimento e mesmo o uso de tranquilizantes não foi necessário.

A metodologia utilizada para a separação das células mononucleares do aspirado medular por gradiente de densidade com o uso de Ficoll, bem como a determinação da viabilidade celular utilizando-se o Azul de Trypan também foi considerada simples e eficiente, e já havia sido utilizada com sucesso por outros pesquisadores (Renzi et al. 2012).

A fração vascular estromal do tecido adiposo é constituída de uma população heterogênia de células que inclui células-tronco mesenquimais, células endoteliais progenitoras, células-tronco hematopoiéticas, fibroblastos e outras. Esta suspensão de células pode ser usada no tratamento de lesões articulares, de tendões e ligamentos logo após o diagnóstico, ou pode ser expandida em cultura para isolamento das células-tronco mesenquimais derivadas do tecido adiposo (Gutierrez-Nibeyro 2011). Segundo Nixon et al. (2008), a fração vascular estromal do tecido adiposo tem sido uma fonte popular de células regenerativas para o tratamento de injúrias musculoesqueléticas de equinos na América do Norte porque um grande número de células nucleadas com potencial anti-inflamatório e efeitos regenerativos é obtido de cada amostra com 24-48 horas da coleta de tecido.

A metodologia utilizada neste trabalho para a obtenção da fração vascular estromal do tecido adiposo foi semelhante à utilizada por Carvalho et al. (2009) e mostrou-se muito eficiente, uma vez que foi obtido um ótimo percentual de viabilidade celular (média de 96\%).

Segundo Zuk et al. (2002), o tecido adiposo seria importante fonte alternativa de células-tronco mesenquimais, uma vez que normalmente se obtém um número muito baixo destas células a partir da medula óssea. Neste trabalho, o número de células mononucleares obtidas em um milili- 
tro de aspirado medular foi superior (embora estatisticamente semelhante) ao número de células presentes em um grama de tecido adiposo. Estes resultados estão de acordo com os relatados por Vidal et al. (2007), que obtiveram número de células mononucleares nas amostras de aspirado medular $\left(64 \times 10^{5}\right)$ superior àquele encontrado no tecido adiposo $\left(3 \times 10^{5}\right)$. No entanto, é importante lembrar que este número representa todas as células mononucleares e não somente células-tronco mesenquimais. Segundo Taylor \& Clegg (2011), a concentração de células-tronco mesenquimais na fração mononuclear da medula óssea varia de 0,001-0,01\% e, de acordo com Dalhgren (2009), representa cerca de $1-3 \%$ do total de células nucleadas da fração estromal do tecido adiposo. 0 número de células-tronco mesenquimais obtido de aspirados de medula óssea é considerado muito baixo para promover um efeito regenerativo primário. No entanto, estudos in vitro têm demonstrado que células-tronco mesenquinais provenientes de medula óssea apresentam um potencial de diferenciação superior às células-tronco derivadas de tecido adiposo, sugerindo que a medula óssea seja melhor como fonte de células para regeneração de tecidos musculoesqueléticos em cavalos. Porém, esta diferença ainda não tem sido demonstrada in vivo (Gutierrez-Nibeyro 2011).

A diminuição da viabilidade celular observada neste trabalho após o descongelamento das amostras indica que tanto as células da fração mononuclear da medula óssea quanto da fração estromal do tecido adiposo sofreram com o processo de criopreservação. Sabe-se que este processo induz danos à estrutura celular (Cury \& Guarita-Souza 2007) e o objetivo dos vários protocolos de criopreservação é minimizar a injúria celular durante o processo de congelamento e descongelamento. Esta injúria pode resultar da extensiva desidratação celular e/ou devido à formação intracelular de cristais de gelo. Além disso, um alto grau de destruição celular está relacionado à liberação de calor de fusão observada quando o período de transição entre as fases líquida e sólida se prolonga excessivamente (Balint et al. 1999).

De acordo com Pamphilon (2004), entre os fatores que afetam a eficácia da criopreservação destacam-se: a velocidade de congelamento, o controle da temperatura e a concentração do agente crioprotetor. Os cristais de gelo intracelulares, que muitas vezes promovem a ruptura mecânica das células, são formados durante o processo de congelamento rápido. No congelamento gradativo, com decréscimo gradual e constante da temperatura, a formação de gelo será primariamente extracelular. No entanto, a formação de cristais de gelo no meio extracelular também é prejudicial, pois ocasiona desequilíbrio osmótico entre os meios intra e extracelular (Pegg 2006). 0 desequilíbrio osmótico tem como consequência a lesão da membrana plasmática, podendo resultar em ruptura e morte celular (Meryman 2007).

Para que o processo de criopreservação tenha sucesso, é necessário o uso de um agente crioprotetor que diminua o gradiente osmótico e a diferença de pressão de vapor entre os compartimentos intra e extracelular (Balint et al. 1999). As soluções crioprotetoras são classificadas de acordo com a sua capacidade de atravessar a membrana plasmática. Os crioprotetores intracelulares, como o Dimetilsulfóxido (DMSO), o etilenoglicol e o glicerol, são moléculas pequenas, cuja função é reduzir a expansão do volume celular que ocorre durante o congelamento lento e o descongelamento rápido (Hunt 2011). Os crioprotetores extracelulares são polímeros de cadeia longa, polipeptídeos ou carboidratos capazes de desidratar a célula antes do congelamento reduzindo, então, a formação de cristais de gelo intracelulares. A solução de DMSO a 10\%, utilizada neste trabalho, frequentemente é considerada o meio de criopreservação mais eficiente e tem sido usada por décadas para preservar muitos tipos de células e tecidos (Matsumura \& Hyon 2009).

No entanto, alguns trabalhos têm observado diferenças na viabilidade celular após o descongelamento conforme a substância crioprotetora utilizada. Oichi et al. (2008) avaliaram sete diferentes protocolos para criopreservação de células-tronco derivadas de tecido adiposo de camundongos e verificaram as menores porcentagens de viabilidade celular quando foi utilizado DMSO a $10 \%$ ou meio de criopreservação com glicerol. Estes autores sugeriram a utilização de substâncias crioprotetoras não tóxicas às células como a trealose (um dissacarídeo de glicose) em vez de DMSO, que apresenta maior toxicidade. Entretanto, Renzi et al. (2012) avaliaram a viabilidade após o descongelamento de células estromais obtidas da medula óssea de cavalos, ovelhas e ratos e de tecido adiposo de cavalos, testando quinze soluções de criopreservação com diferentes concentrações de DMSO e de outros crioprotetores, e encontraram os melhores resultados de viabilidade celular com o uso da solução contendo $10 \%$ de DMSO. 0 estudo foi motivado porque estes pesquisadores têm observado, em suas atividades de rotina, uma grande sensibilidade das células estromais da medula óssea de equinos ao processo de congelamento e descongelamento, com grande diminuição do número de células viáveis e da capacidade de replicação. De fato, os resultados obtidos confirmaram a baixa resistência das células mononucleares da medula óssea de equinos aos danos intracelulares causados pelos cristais de gelo, e a viabilidade celular não foi superior a 50\%. Já as células estromais do tecido adiposo apresentaram uma boa viabilidade e capacidade de replicação após o descongelamento.

No entanto, no presente trabalho, foram observados resultados diferentes dos encontrados por Renzi et al. (2012). As células mononucleares da medula óssea de equinos, embora tenham apresentado uma redução significativa após o processo de criopreservação, apresentaram uma viabilidade média de $86 \%$. Por outro lado, as amostras de células estromais do tecido adiposo foram mais sensíveis ao processo de criopreservação e diminuíram a viabilidade para $64 \%$ após o descongelamento.

Assim, diante das divergências encontradas, da carência de trabalhos que abordem o assunto e da importância que a terapia celular tem ganhado na clínica médica de equinos, conclui-se que é necessária a realização de outros estudos que avaliem um grande número de amostras e diferentes protocolos de congelamento, a fim de padronizar uma téc- 
nica que garanta altos níveis de viabilidade celular e preserve as características originais das células mononucleares da medula óssea e da fração vascular estromal do tecido adiposo de equinos.

Agradecimentos.- À Fundação de Amparo à Pesquisa do Estado de São Paulo (FAPESP) pelo apoio financeiro recebido (2010/52480-8) e pela bolsa de doutorado de Camila E. Barroso (2008/58096-5).

\section{REFERÊNCIAS}

Balint B., Ivanovic Z., Petakov M., Taseski J., Joveie G., Stojanovie N. \& Milenkovie P. 1999. The cryopreservation protocol optimal for progenitor recovery is not optimal for preservation of marrow repopulating ability. Bone Marrow Transplant. 23:613-619.

Bittencourt R.A.C., Pereira H.R., Felisbino S.L., Murador P., Oliveira A.P.E. \& Deffune E. 2006. Isolamento de células-tronco mesenquimais da medula óssea. Acta Ortop. Bras. 14:1-6.

Carvalho A.M., Alves A.L.G., Golim M.A., Moroz A., Hussni C.A., Oliveira P.G. G. \& Deffune E. 2009. Isolation and immunophenotypic characterization of mesenchymal stem cells derived from equine species adipose tissue. Vet. Immunol. Immunopathol. 132:303-306.

Crovace A., Lacitignola L., Rossi G. \& Francioso E. 2010. Histological and immunohistochemical evaluation of autologous cultured bone marrow mesenchymal stem cells and bone marrow mononucleated cells in collagenase-induced tendinitis of equine superficial digital flexor tendon. Vet. Med. Int. Article ID 250978.

Cury C.C. \& Guarita-Souza L.C. 2007. The cultivated bone marrow-derived mesenchymal stem cells viability analysis after cryopreservation: experimental study in rats. Estud. Biol. 29 Article ID 1691. (Resumo)

Dahlgren L.A. 2009. Stem Cell Therapy, p.908-911. In: Robinson N.E. \& Sprayberry K.A. (Eds), Current Therapy in Equine Medicine. $6^{\text {th }}$ ed. Saunders Elsevier, St Louis.

Durando M., Zarucco L. \& Schaer T. 2006. Pneumopericardium in a horse secondary to sternal bone marrow aspiration. Equine Vet. Educ.18:7579.

Fortier L.A. \& Smith R.K. 2008. Regenerative medicine for tendinous and ligamentous injuries of sport horses. Vet. Clin. North Am., Equine Pract. 24:191-201.

Fraser J.K., Zhu M., Wulur I. \& Alfonso Z. 2008. Adipose-derived stem cells. Methods Mol. Biol. 449:59-67.

Gutierrez-Nibeyro S.D. 2011. Commercial cellbased therapies for musculoskeletal injuries in horses. Vet. Clin. Equine 27:363-371.

Hunt C.J. 2011. Cryopreservation of human stem cells for clinical application: a review. Transfus. Med. Hemother. 38:107-123.

Oishi K., Noguchi H., Yukawa H., Miyazaki T., Kato R., Kitagawa Y., Ueda M. \& Hayashi S. 2008. Cryopreservation of mouse adipose tissue-derived stem/progenitor cells. Cell Transplant. 17:35-41.
Martinello T., Bronzini I., Maccatrozzo L., Iacopetti I., Sampaolesi M., Mascarello F. \& Patruno M. 2010. Cryopreservation does not affect the stem characteristics of multipotent cells isolated from equine peripheral blood. Tissue Eng. C, Methods 16:771-781.

Matsumura K. \& Hyon S.H. 2009. Polyampholytes as low toxic efficient cryoprotective agents with antifreeze protein properties. Biomaterials 30:4842-4849.

Meryman H.T.2007. Cryopreservation of living cells: principles and practice. Transfusion 47:935-945.

Nixon A.J., Dalgren L.A., Haupt J.L. Yeager A.E. \& Ward D.L. 2008. Effect of adipose-derived nucleated cell fractions on tendon repair in horses with collagenase-induced tendinitis. Am. J. Vet. Res. 69:928-937.

Oliveira P.G.G., Alves A.L.G., Carvalho A.M., Hussni C.A., Watanabe R.L., Rodrigues M.M.P. \& Mota L.S. 2011. Uso de células mononucleares da medula óssea no tratamento de tendinites induzidas experimentalmente em equinos. Arq. Bras. Med. Vet. Zootec. 63:1391-1398.

Pacini S., Spinabella S., Trombi L., Fazzi R., Galimberti S., Dini F., Carlucci F. \& Petrini M. 2007. Suspension of bone marrow-derived undifferentiated mesenchymal stromal cells for repair of superficial digital flexor tendon in race horses. Tissue Eng. 13:2949-2955.

Pamphilon D. 2004. Stem-cell harvesting and manipulation. Vox Sang. 87:20-25.

Pegg D.E. 2006. The preservation of tissues for transplantation. Cell Tissue Bank 7:349-358.

Renzi S., Lombardo T., Dotti S., Dessi S.S., De Blasio P. \& Ferrari M. 2012. Mesenchymal stromal cell cryopreservation. Biopreserv. Biobanking 10:276-281

Smith R.K.W., Korda M., Blunn G.W. \& Goodship A. 2003. E. Isolation and implantation of autologous mesenchymal stem cells from bone marrow into the superficial digital flexor tendon as a potential novel treatment. Equine Vet. J. 35:99-102.

Sumida S. 2006. Transfusion and transplantation of cryopreserved cells and tissues. Cell Tissue Bank 7:265-305.

Taylor S.E. \& Clegg P.D. 2011. Collection and propagation methods for mesenchymal stromal cells. Vet. Clin. North Am., Equine Pract. 27:263-274.

Toma J.G., Akhavan M., Fernandes K.J., Barnabé-Heider F., Sadikot A., Kaplan D.R. \& Miller F.D. 2001. Isolation of multipotent adult stem cells from the dermis of mammalian skin. Nat. Cell Biol. 3:778-784.

Vidal M.A., Kilroy G.E., Lopez M.J., Johnson J.R., Moore R.M. \& Gimble J.M. 2007. Characterization of equine adipose tissue-derived stromal cells: adipogenic and osteogenic capacity and comparison with bone marrow-derived mesenchymal stromal cells. Vet. Surg. 36:613-622.

Zuk P.A., Zhu M., Ashjian P., De Ugarte D.A., Huang J.I., Mizuno H., Alfonso Z.C., Fraser J.K., Benhaim P. \& Hedrick M.H. 2002. Human adipose tissue is a source of multipotent stem cells. Mol. Biol. Cell 13:4279-4295.

Zuk P.A., Zhu M., Mizuno H., Huang J., Futrell J.W., Katz A.J., Benhaim P., Lorenz H.P. \& Hedrick M.H. 2001. Multilineage cells from human adipose tissue: implication for cell-based therapies. Tissue Eng. 7:211-228. 